\title{
Aneurysm of the mitral valve complicating Streptococcus milleri endocarditis
}

\author{
AKINDELE P. AKINJIDE-OBONYO \\ M.R.C.P. \\ HENRI MOUSSALLI \\ F.R.C.S.
}

\author{
COLIN L. BRAY \\ F.R.C.P. \\ DAVID C. BETON \\ D.M.R.D.
}

\author{
T. NigEl StANBRIDGE \\ M.D. \\ Wythenshawe Hospital, Manchester M23 9LT
}

\begin{abstract}
Summary
A case of Streptococcus milleri endocarditis which caused an aneurysm of the anterior leaflet of the mitral valve is reported. There is only one previous report of a mitral valve aneurysm secondary to infective endocarditis demonstrated by angiography. Streptococcus milleri normally causes endocarditis in an older age group than the patient we describe. Some salient features of this increasingly recognized human pathogen are emphasized.
\end{abstract}

KEY WORDS: aneurysm, endocarditis, streptococcus, mitral valve.

\section{Introduction}

Good evidence has been presented for the pathogenic role of Streptococcus milleri (Parker and Ball, 1976). This organism is the cause of brain abscesses, meningitis, pleural empyema and a variety of intraabdominal abscesses; it accounts for $29 \%$ of streptococcal infections in these sites (Parker and Ball, 1976). It is also a rare cause of infective endocarditis and accounts for $5.4 \%$ of 317 bacteriologically proven cases in one report (Parker and Ball, 1976), and 5\% of 68 cases in another (Murray et al., 1978).

\section{Case report}

A 27 -year-old motor car mechanic was admitted to another hospital with a 4 week history of malaise, anorexia and $8 \mathrm{~kg}$ weight loss. There was no recent history of dental extraction. He had a successful resection of an aortic coarctation at the age of 7 years,

Request for reprints to: Dr C. L. Bray, Department of Cardiology, Regional Cardiac Centre, Wythershawe Hospital, Southmoor Road, Manchester M23 9LT and aortic incompetence was first diagnosed on routine follow-up at the age of 20 years. On $\frac{}{5}$ examination, he was pyrexial, $38.8^{\circ} \mathrm{C}$, with finger $\overrightarrow{ }$ clubbing, severe dental caries and hepatomegaly. He had sinus tachycardia of 120 per min, blood pressure of $145 / 45 \mathrm{mmHg}$. a loud and long eardy $\overrightarrow{0}$ diastolic murmur at the left sternal edge and $\underset{c}{\infty}$ moderately loud and long mid-diastolic murmur at the apex. His white cell count was $17.3 \times 10^{9} /$ litre? (85\% neutrophils), haemoglobin $9.7 \mathrm{~g} / \mathrm{dl}$, albumin 30 $\mathrm{g} /$ litre and normal urea, creatinine and liver enzymes. Chest X-ray showed a normal heart size $\stackrel{\circ}{\mathbb{Q}}$ and configuration with no pulmonary venous congestion. The electrocardiogram showed a sinus tachycardia only. Echocardiography showed the fine oscillations of the mitral anterior leaflet, characteristic of aortic incompetence, with vegetations behind the valve.

Streptococcus milleri, sensitive to a minimum. inhibitory concentration of penicillin of $0.01 \mu \mathrm{g} / \mathrm{ml} 3$ was isolated from 3 bottles. This organism had the following characteristics: (1) It was a Gram positive 3 coccus which formed non-haemolytic colonies on blood agar, and grew aerobically, anaerobically, and in carbon dioxide. (2) It grew on $40 \%$ bile agar, but $\frac{7}{0}$ not on $6.5 \%$ sodium chloride. (3) It hydrolyzed aesculin, produced ammonia from arginine and was $\tilde{N}$ Voges-Proskauer (VP) positive. (4) It produced acid $\sim$ from lactose, glucose, maltose, sucrose, trehalose and salicin. (5) This strain had a Lancefield group $C_{0}^{\omega}$ antigen demonstrable by acid extraction. (6) The organism was sensitive to penicillin, tetracycline, $\stackrel{\varrho}{\subseteq}$ erythromycin and ampicillin.

Treatment with cephradine $1 \mathrm{~g}$ i.v. 6 hourly and? gentamicin $80 \mathrm{mg}$ i.m. 8 hourly was given because it was thought that he was allergic to penicillin. The fever settled within $72 \mathrm{hr}$ of starting treatment but $\frac{\odot}{\mathbb{Q}}$ 


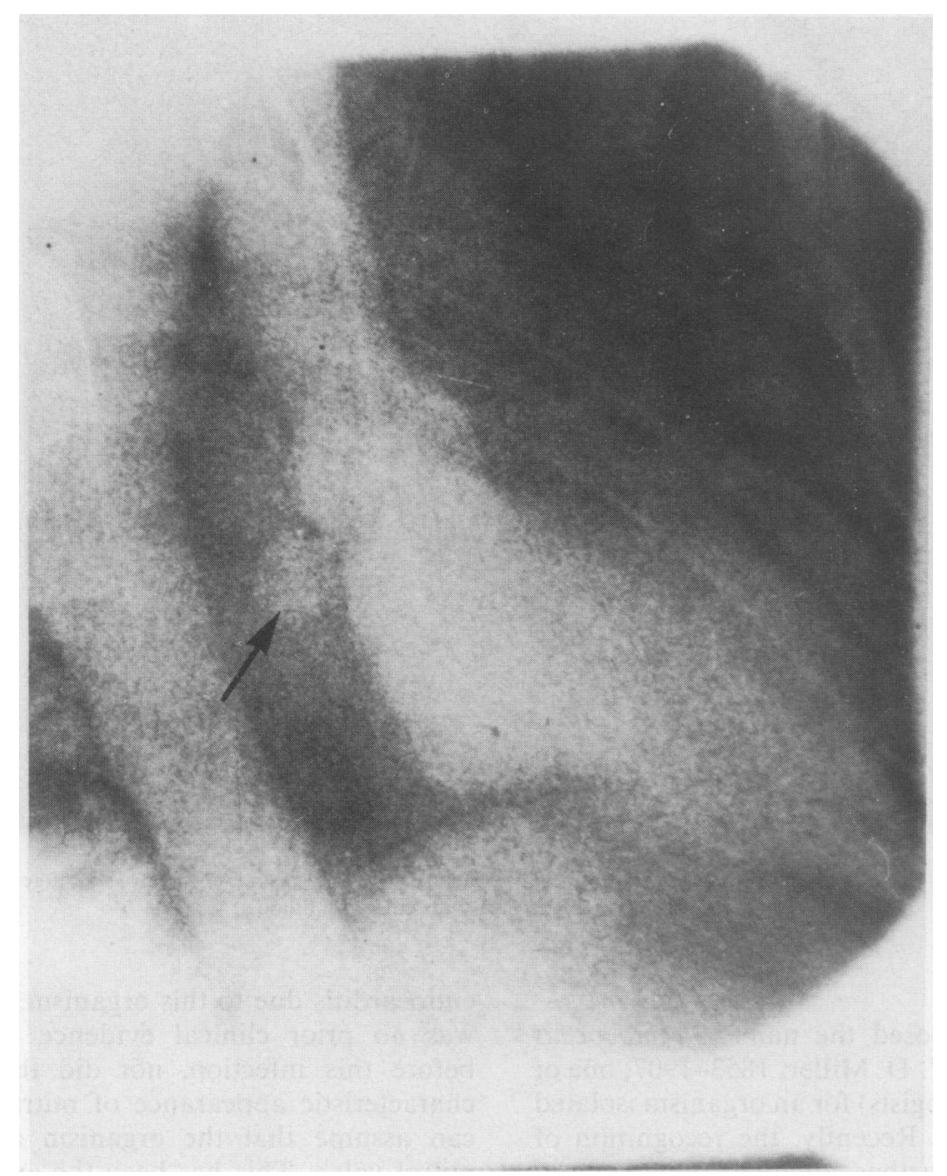

FIG. 1. 16mm cine-angiogram in right anterior oblique view showing true aneurysm of the anterior mitral valve cusp (arrowed).

recurred 5 days later; after a further 3 days of pyrexia he was transferred to our hospital. Fortunately, the suspicion of penicillin allergy was ill-founded and benzyl penicillin 3 megaunits i.v. 4 hourly and gentamicin $80 \mathrm{mg}$ i.m. 8 hourly were started. On this dosage, minimal and maximal bacteriocidal levels of antibiotic in the serum of 1 in 32 and 1 in 512 respectively were attained. Gentamicin levels were kept between $1.5-1.8 \mu \mathrm{g} / \mathrm{ml}$ pre-dose and 3.0-6.5 $\mu \mathrm{g} / \mathrm{ml}$ post-dose throughout. He was treated thus for 4 weeks and then the intravenous penicillin changed to amoxycillin $3 \mathrm{~g}$ 4-hourly orally. His fever settled permanently within $48 \mathrm{hr}$ of starting penicillin and gentamicin.

Cardiac catheterization, 4 weeks after admission to our unit, showed severe aortic regurgitation, a pulmonary systolic pressure of $40 \mathrm{mmHg}$, pulmonary capillary venous pressure of $22 \mathrm{mmHg}$ and a mitral valve end-diastolic gradient of $10 \mathrm{mmHg}$. The left ventricular angiogram showed no mitral regurgitation, but there was an aneurysm of the mitral valve (Fig. 1).

At open heart surgery, carried out one week after catheterization, the aortic valve was found to be thickened with calcification in places and was grossly incompetent. The mitral valve orifice was partly obstructed by dense vegetations which originated predominantly from the anterior cusp. In the centre of that cusp was a true aneurysm which communicated with the left ventricular outflow tract by a small opening of $0.7 \mathrm{~cm}$ in diameter (Fig. 2). The mitral valve was replaced with a number 4 Starr-Edwards valve type 6120 and the aortic valve was replaced with a number 10 Starr-Edwards valve type 1260 . Histology confirmed active endocarditis of the mitral valve but not of the aortic valve. His post-operative course was uneventful and he was discharged home 2 weeks after surgery. 


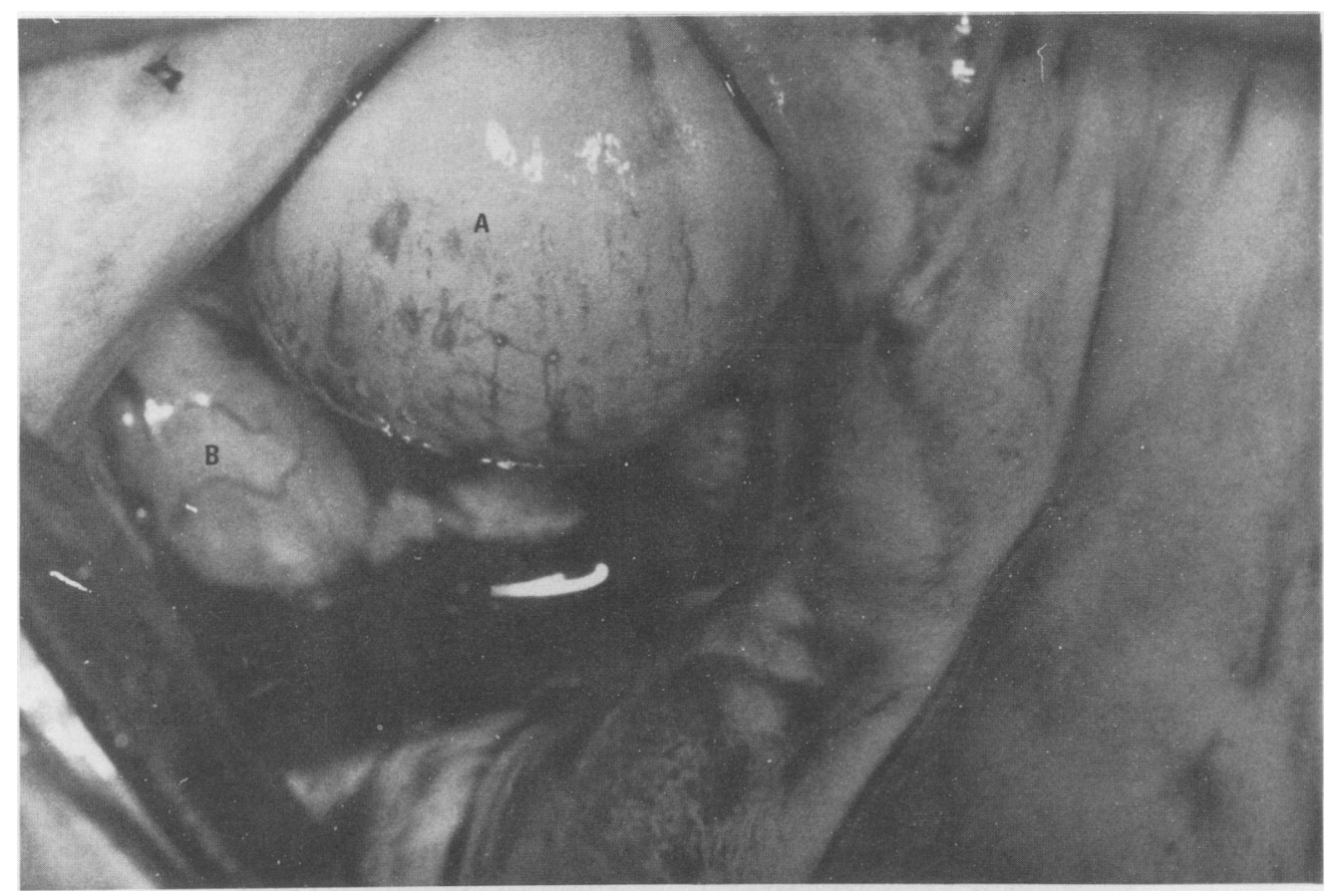

FIG. 2. Appearance of mitral valve at operation as seen through the left atrium. The aneurysm (A) is seen as a bulge of the anterior cusp. posterior leaflet $(B)$ is partly obscured by blood.

\section{Discussion}

Guthof (1956) proposed the name Streptococcus milleri (in honour of W. D. Miller, 1853-1907, one of the first oral microbiologists) for an organism isolated from dental abscesses. Recently, the recognition of this species has been further advanced (Colman and Williams, 1972) and its characteristics found to be similar to streptococcus sp. MG (Mirick et al., 1944). S.milleri is a heterogeneous group in which $80 \%$ of strains hydrolyse arginine and aesculin, have a positive Voges-Proskauer reaction and acidify trehalose, lactose, salicin and sucrose (Ball and Parker, 1979). Most of the strains are non-haemolytic and ungroupable, but $25 \%$ are $\beta$-haemolytic and $19 \% \alpha$ haemolytic: $28 \%$ possess a Lancefield group antigen in decreasing order of frequency $F, G, A$ and $C$ (Ball and Parker, 1979).

In one report of 17 cases of S.milleri endocarditis, all patients were older than 35 years (Parker and Ball, 1976), and in another, all 3 cases had a major complication; septic arthritis and a splenic abscess developed in 2 patients and the third patient died after developing disseminated intravascular coagulation (Murray $\epsilon t$ al., 1978). This present case adds another unusual complication, a true aneurysm of the anterior leaflet of the mitral valve. This patient was also younger than is usual in patients with endocarditis due to this organism. In addition, there was no prior clinical evidence of mitral stenosis $\stackrel{\circ}{\mathbb{Q}}$ before this infection, nor did the valve have the characteristic appearance of mitral stenosis, so one $\stackrel{0}{\circ}$ can assume that the organism affected a normal mitral valve. This has been the experience of others? (Parker and Ball, 1976). Aneurysms of the mitral valve secondary to infective endocarditis have been $\frac{3}{3}$ described (Edwards, 1972; Barack et al., 1977; Gonzalez-Lavin, Somerville, and Ross, 1972). However, there is only one previous report of the radiological demonstration of an aneurysm, which was complica- $\frac{\beta}{3}$ ting Straphylococcus aureus endocarditis (Barack et al., 1977). In these cases, the mitral valve is usually secondarily involved from an infection of the aortic valve (Barack et al., 1977; Gonzalez-Lavin et al., 1972; Saphir and Leroy, 1948). This may cause a jet $\mathcal{N}$ lesion' which can lead to pitting, ulcerations, vegeta- N tions and perforation (Gonzalez-Lavin et al., 1972). Aneurysms may be true or false. In the case of a true ${ }^{\omega}$ aneurysm, the initial lesion is a valvulitis with consequent formation of granulation tissue and, as $\stackrel{\circ}{\subset}$ healing sets in, the scar tissue formed succumbs to intraventricular pressure with the formation of a sac- like out-pouching (Saphir and Leroy, 1948). This means that the formation of a true aneurysm is a $\vec{D}$ consequence of the healing process and is more likely $\frac{\mathbb{Q}}{\mathbb{D}}$ 
to occur in those who are successfully treated with antibiotics (Saphir and Leroy, 1948). Clearly, had we not proceeded to cardiac catheterization the lesion would not have been discovered.

Patients with infective endocarditis and aortic incompetence who have echocardiographic evidence of vegetations, but are not in congestive heart failure and have no clinically obvious embolic episodes, can pose a management dilemma (Stiles and Friesinger, 1980). We propose that the practice of cardiac catheterization should be more widely considered, even in those who are successfully treated with chemotherapy. This case would also lend support to the suggestion already made that patients with infective endocarditis due to this organism should be carefully monitored both during and after appropriate antimicrobial therapy (Murray et al., 1978).

Finally, one may speculate on the site of origin of this organism in our patient. S.milleri is commonly found in the human oral cavity (Mejare and Edwardsson, 1975). Furthermore, there is evidence that the frequency with which it is discovered in infected dental root canals and cervico-facial infections may point to a pathogenic role at these sites (Lutticken et al., 1978). It is possible therefore that the source of the infection in the patient reported here was his carious teeth.

\section{Acknowledgments}

We wish to thank Dr M. D. Winson, consultant physician at Leighton Hospital, and Mr W. K. Douglas, who resected his coarctation, for referring this patient to us.

\section{References}

BALL, L.C. \& PARKer, M.T. (1979) The cultural and biochemical characters of Streptococcus milleri strains isolated from human sources. Journal of Hygiene, 82, 63.
Barack, B.M., Grollman, J.H., JR., Olinger, G.N., Levisman, J.A. \& MACALPIN, R.N. (1977) Mycotic aneurysm of the mitral valve complicating aortic valve endocarditis. American Journal of Roentgenology, 128, 308.

Colman, G. \& Williams, R.E.O. (1972) Taxonomy of some human viridans streptococci. In: Streptococci and Streptococcal Disease, Recognition, Understanding and Management (eds. L. W. Wannamaker and J. M. Matsen), Ch. 17. New York Academic Press, Inc.

EDWARDS, J.E. (1972) Mitral insufficiency secondary to aortic valvular bacterial endocarditis. Circulation, 46, 623.

Gonzalez-Lavin, L., Somerville, J. \& Ross, D.N. (1972) 'Jet Lesion' in aortic valve endocarditis. British Heart Journal, 34, 206.

Guthof, O. (1956) Pathogenic strains of Streptococcus viridans: streptococci found in dental abscesses and infiltrates in the region of the oral cavity. Zentralblatt für Bakteriologie, Parasitenkunde, Infektionskrankheiten und Hygiene, 1..Abt. Ref., 166, 553.

LUTTICKEN, R., WENDORFF, U., LUTTICKEN, D., JOHNSON, E.A. \& WANNAMAKER, L.W. (1978) Studies on streptococci resembling Streptococcus milleri and an associated surface-protein antigen. Journal of Medical Microbiology, 11, 419.

Mejare, B. \& Edwardsson, S. (1975) Streptococcus milleri (Guthof); an endogenous organism of the human oral cavity. Archives of Oral Biology, 20, 757.

Mirick, G.S., Thomas, L., Curnen, E.C. \& Horsfall, F.L. (1944) Studies on a non-haemolytic streptococcus isolated from the respiratory tract of human beings. Journal of Experimental Medicine, 80, 391.

MurRay, H.W., Gross, K.C., MaSUR, H. \& RoberTS, R.B. (1978) Serious infections caused by Streptococcus milleri. American Journal of Medicine, 64, 759.

PARKer, M.T. \& BALl, L.C. (1976) Streptococci and aerococci associated with systemic infection in man. Journal of Medical Microbiology, 9, 275.

SAPHIR, O. \& LEROY, E.P. (1948) True aneurysms of the mitral valve in sub-acute bacterial endocarditis. American Journal of Patho$\log y, 24,83$.

STILES, G.L. \& FRIESINGER, G.C. (1980) Bacterial endocarditis with aortic regurgitation: implications of embolism. Southern Medical Journal, 73, 582.

(Accepted 8th July 1982) 